\title{
Complex landscapes from simple ecohydrological feedbacks
}

\author{
G. S. McGrath ${ }^{\mathrm{a}}$, K. Paik ${ }^{\mathrm{b}}$ and C. Hinz ${ }^{\mathrm{ac}}$ \\ ${ }^{a}$ School of Earth and Environment, The University of Western Australia, M087, 35 Stirling Highway, \\ Crawley, Western Australia, 6009 \\ ${ }^{\mathrm{b}}$ School of Civil, Environmental, and Architectural Engineering, Korea University, Anam-dong 5 ga, \\ Seongbuk-gu, Seoul 136-713, South Korea \\ ${ }^{\mathrm{c}}$ Brandenburg University of Technology, Hydrology and Water Resources Management, \\ Konrad-Wachsmann-Allee 6, 03046 Cottbus, Germany \\ Email: gavan.mcgrath@uwa.edu.au
}

\begin{abstract}
Self-organised vegetation patterns arise in water limited systems as a result of the interaction of short range facilitation and long range competition. On smooth and gently sloped terrain banded vegetation patterns are known to spontaneously emerge as a result of these feedbacks. These ecohydrological interactions can also impact erosion and thus alter the long term variation in surface water redistribution patterns via changes to the topography. We explore the effect of this additional process on the geomorphology and spatial organisation of vegetation. The model is shown capable of reproducing banded vegetation patterns on a smooth hillslope in the absence of erosion. With significant fluvial erosion vegetation bands degrade and instead form a complex network of patchy vegetation colonizing main drainage channels. These channels in turn dissect a lumpy microtopography associated with the patches, containing a characteristic mound scale. This type of landform contains features resembling some real patchy semiarid hills. Decreasing the extent to which plants can locally increase soil hydraulic conductivity causes the resulting landform and vegetation pattern to be significantly different. Models investigating this co-evolution of form and function appear to offer new insights into the dynamics of water limited ecosystems.
\end{abstract}

Keywords: Geomorphology, eco-hydrology, feedbacks. 


\section{INTRODUCTION}

Mosaics of vegetated patches and bare soil in semiarid ecosystems occur as a result of a scale dependent positive and negative feedbacks [Lefever and Lejeune, 1997; Borgogno et al., 2009]. In particular, long range competition for resources (negative feedbacks), such as water, and shorter range facilitation (positive feedbacks), enhancing plant establishment and survival are known to lead to the formation of regular periodic vegetation patterns [Lefever and Lejeune, 1997; Klausmeier, 1999]. Plants facilitate their survival and reproduction by modifying soil to enhance infiltration, shading which lowers soil temperature and soil evaporation as well as increases retention of water and nutrient recycling [Bedford and Small, 2008; Borgogno et al., 2009]. In addition, direct competition occurs between individual plants via laterally extensive root systems [Lefever and Lejeune, 1997] as well as indirect competition between patches of vegetation via the interception of surface runoff [Ludwig et al., 2007]. Visually striking patterns of vegetation, such as regular spots, holes and labyrinths are the classical signatures of these underlying feedbacks on flat terrain [Borgogno et al., 2009]. Regular banded vegetation patterns, typically aligned perpendicular to the predominant topographic gradient, are also known to form on gently sloping hills as a result of these interactions [Klausmeier, 1999].

The lateral redistribution of water by runoff also has the consequence that some sediments are eroded and deposited downslope, altering the direction and intensity of water flow pathways. This potentially has cascading impacts on self-organised vegetation patterns via the indirect competition mechanism described above. There is ample field evidence that there are strong interactions between runoff, erosion and patchy vegetation [Sanchez and Puigdefabregas, 1994; Ludwig et al., 2005; Puigdefabregas, 2005; Ludwig et al., 2007; Marston, 2010]. For example, observations on Mediterranean hills describe small scale vegetation patches which intercept surface runoff and sediments creating small terraces or mounds [Cammeraat and Imeson, 1999; Sanchez and Puigdefabregas, 1994]. Gallart et al. [1993] showed that the growth and form of some tussock grasses were strongly influenced by the surface gradient, the intensity of sediment flux and water redistribution patterns. Also, Puigdefabregas and Pugnaire (as cited in Puigdefabregas et al. [1999]) suggested differences in patch shape along a hillslope were related to differences in the sediment transport capacity, where rounded patches gave way to more banded (oriented across slope) and then to oblate (oriented downslope) shapes with successive increases in transport capacity. Disturbance of banded vegetation systems was also shown to greatly increase erosion and degradation of the banded structure [Ludwig et al., 2005].

While several models have been developed to ascertain how erosion responds to specified vegetation organisation [Boer and Puigdefabregas, 2005], few have considered the coupling of vegetation selforganisation and erosion [Saco et al., 2007]. In the context of patchy vegetation systems, two notable studies have investigated such interactions. They both reproduced terraced microtopograpy and banded vegetation organisation [Gallart et al., 1993; Saco et al., 2007]. However, water flow in these instances remained predominantly unidirectional and thus the flow field was little altered by the spatial distribution of plants. Here we developed a model to investigate such interactions with the specific intention of exploring more dynamic alteration of flow directions. It is hoped that this will improve our understanding of how to better manage these complex systems.

\section{MODEL}

The model combines the following three components: (i) a simple spatially distributed water balance with Hortonian overland flow, infiltration, soil evaporation and transpiration by individual plants; (ii) a rule based approach to vegetation establishment and death; and (iii) a landscape evolution model which alters the topography and flow directions in response to surface water fluxes. The spatial distribution of vegetation determines the spatial organization of soil properties and thus infiltration and surface water redistribution through the landscape. The landscape responds to these fluxes, each time slightly modifying its form via erosion. Vegetation in turn utilizes water stored in the soil and depending upon competitive interactions each plants grow, die, or establish redefining their spatial organization . 


\subsection{Water balance}

The water balance at a point in lattice of square cells is simulated by the following:

$\frac{\mathrm{d} w_{i}}{\mathrm{~d} t}=P_{i}+R_{i}-Q_{i}-E_{i}-\sum_{n} T_{n}$

The units of the various terms are defined here with respect to arbitrary time (T), length (L), and later mass (M) units. The subscript $i$ refers to the spatial location, $t$ denotes time, $w[\mathrm{~L}]$ water storage depth, $P$ [L T $\left.{ }^{-1}\right]$ the rainfall rate, $R\left[\mathrm{~L} \mathrm{~T}^{-1}\right]$ the rate of surface water run-on, $Q\left[\mathrm{~L} \mathrm{~T}^{-1}\right]$ the rate of surface water runoff, $E\left[\mathrm{~L} \mathrm{~T}^{-1}\right]$ the evaporation rate from soil and $T\left[\mathrm{~L} \mathrm{~T}^{-1}\right]$ denotes the amount of transpiration by plants located at $i$ as well as all neighbouring plants with laterally extensive roots that extend to $i$.

Infiltration and surface runoff. Surface runoff occurs along flow directions determined by the GD8 algorithm [Paik, 2008]. This algorithm reduces significantly errors in the determination of flow directions in comparison to the more commonly used D8 algorithm, particularly when the principal flow direction is not oriented along one of the main eight directions of a square lattice. Infiltration of a discrete water particle is considered to occur with a probability $p_{i}=\min \left(K_{i} / P_{i}, 1\right)$ which depends upon the rain rate $P_{i}$ $\left[\mathrm{L} \mathrm{T}^{-1}\right]$ and the soil's hydraulic conductivity $K_{i}\left[\mathrm{~L} \mathrm{~T}^{-1}\right]$. Flow accumulation impacting this probability is neglected as our current focus is on landscapes with low relief. This provides a simplistic algorithm which nonetheless can easily be shown to reproduce the phenomena seen in many semi-arid systems where discharge, per unit hillslope length, decreases as the length of the hillslope increases [Lavee and Yair, 1990; Stomph et al., 2002]. This results from a variety of mechanisms including microtopographic variations in soil hydraulic conductivity, variation in runoff depth and the interaction between runoff and rainfall time scales [Lavee and Yair, 1990; Dunne et al., 1991].

The infiltration rate is controlled by the local density of plants. This facilitative effect tends to decrease with distance from a plant [Bedford and Small, 2008]. We account for this effect using a Gaussian kernel [Lefever and Lejeune, 1997] such that the soil hydraulic conductivity is determined via:

$K_{i}=K_{0}+K_{v} \int b(r) f_{f}(r) \mathrm{d} r$

where the integration is over the entire spatial domain, $K_{i}\left[\mathrm{~L} \mathrm{~T}^{-1}\right]$ is the hydraulic conductivity of the soil at location $i, K_{0}\left[\mathrm{~L} \mathrm{~T}^{-1}\right]$ is the soil's intrinsic hydraulic conductivity, i.e. what it would be in the absence of any plants, $b(r)$ is a function equal to one when a plant is located at a distance $r$ from location $i$ and zero otherwise and $f_{f}(r)=c \exp \left(-k_{f}^{2} r^{2}\right)$ is the Gaussian kernel ( $c$ being the normalising constant) with a facilitation parameter $k_{f}\left[\mathrm{~L}^{-1}\right]$, determining the effective spatial extent of an individual plant's local impact on the soil's hydraulic conductivity.

Evaporation and transpiration. Bare soil evaporation $E_{s}\left[\mathrm{~L} \mathrm{~T}^{-1}\right]$ is a local process that is also affected by the presence of plants. In this study we assume the local facilitative effect of a plant is to reduce soil evaporation under a plant canopy $\left(E_{v}\right)$ to half that of an unvegetated soil [Gwenzi, 2011]. The impact of variations in soil hydraulic conductivity on soil evaporation is assumed negligible.

Transpiration on the other hand is a spatially distributed, competitive phenomena. As with the facilitative effect on soil hydraulic conductivity, we assume that an individual plant has a Gaussian distribution of uptake rates in its neighbourhood. At a distance $r$ from a plant, located at $i$, the rate of water uptake from storage by that plant is given by:

$T_{i}(r)=c T_{\max } \exp \left(-k_{c}^{2} r^{2}\right)$

where again $c$ is a normalising constant, to ensure $c \int_{0}^{r} \exp \left(-k_{c}^{2} r^{\prime 2}\right) \mathrm{d} r^{\prime}=1$, and $T_{\max }\left[\mathrm{L} \mathrm{T}^{-1}\right]$ denotes the maximum annual transpiration rate. $T_{\max }$ is a variable, depending upon the physiological requirements of a particular species and the potential energy available for evaporation. We have assumed there is no biomass dependence on $T_{\max }$ nor is there diversity in plant water use strategies. The time step used in modelling evaporation and transpiration is given by $\Delta t=d / T_{\max }$, where $d$ denotes the area weighted 
volume $\left[\mathrm{L}^{3} \mathrm{~L}^{-2}\right]$ of a water particle $(4 \mathrm{~mm})$. As soil evaporation rates are typically less than transpiration rates the resulting probabilities of evaporation of water particles from bare and vegetation sites can be calculated on the basis of this time scale.

\subsection{Plant growth and death}

Plant establishment depends upon a threshold amount of stored water $w_{c}$ remaining in the soil profile at a location at the end of each year. This is water that has not been utilized during competition by established plants and thus is available for the maturation of a young woody plant. If $w_{i}>w_{c}$ then a bare site transitions to a vegetated state. On the other hand if an individual plant failed to transpire a threshold amount, $T_{c}\left[\mathrm{~L} \mathrm{~T}^{-1}\right]$, of water during the year due to the lack of stored water or excessive competition form other plants, then it sheds an increment of biomass $\Delta b\left[\mathrm{M} \mathrm{L}^{-2} \mathrm{~T}^{-1}\right]$. At zero biomass the site transitions to bare. Plants transpiring sufficiently accumulate an increment of biomass $(\Delta b)$ up to a maximum biomass $b_{\max }\left[\mathrm{M} \mathrm{L}^{-2}\right]$.

\subsection{Landscape evolution}

Change in the surface topography as a result of fluvial incision and diffusive sediment transport is simulated by the following sediment mass balance [Paik and Kumar, 2008]:

$(1-n) \rho_{b} l \frac{\partial z}{\partial t}+\frac{\partial Q_{s}}{\partial x}+D \nabla^{2} z=0$

where $z[\mathrm{~L}]$ is the surface elevation, $Q_{s}\left[\mathrm{M} \mathrm{T}^{-1}\right]$ the sediment load, $x[\mathrm{~L}]$ the distance along a streamline, $t$ is time, $n[-]$ the soil porosity, $\rho_{b}\left[\mathrm{M} \mathrm{L} \mathrm{L}^{-3}\right]$ the soil bulk density, $l[\mathrm{~L}]$ the effective erosion width, and $D\left[\mathrm{M} \mathrm{L}^{2} \mathrm{~T}^{-1}\right]$ a diffusion rate, where we have assumed the local diffusive sediment flux is proportional to the local gradient. We calculate sediment discharge based on the annual water discharge $Q\left[\mathrm{~L}^{3} \mathrm{~T}^{-1}\right]$, with an empirical Schoklitsch type equation [Paik and Kumar, 2008]:

$Q_{s}=\frac{7000}{\sqrt{r}} S^{2 / 3} Q$

where $S$ is the slope [ $\mathrm{L} \mathrm{L}^{-1}$ ], and $r$ [L] an erosion resistance parameter. In this analysis we consider only the possibility that plant feedbacks impact the flow resistance term $r$. Values of $r$ at bare sites are assumed to be uniformly distributed in the range 1-4 mm, while at vegetated sites $r$ occurs in the range 4-40 mm. A new flow resistance value is assigned when a site transitions between vegetated and bare. This simple landform evolution model neglects self-armouring, soil production, bedrock depth, tectonic processes, sediment feedbacks to flow and a variety of other erosion phenomena that may be relevant to specific systems.

\section{RESUlts AND Discussion}

We present here two cases, varying in the strength of the facilitative feedback between plants and soil, to illustrate how such a feedback can radically alter the landform. We also focus here on a set of specific soil and plant parameters that give rise to banded vegetation on smooth terrain. The first case study, in which facilitation is relatively strong $\left(k_{f}=0.6 \mathrm{~m}^{-1}\right)$, begins with a smooth hillslope upon which vegetation is initially distributed randomly. Erosion is commenced after a short period to clearly demonstrate its potential to radically alter vegetation patterns. In the second case study, plants have a more localised influence on soil properties $\left(k_{f}=2.6 \mathrm{~m}^{-1}\right)$, however we assume their impact upon erosion parameters remains the same. Parameters for each case are summarised in Table 1.

It can be seen from this first example, that small plant patches quickly expand, gradually capturing more of the water moving downslope (Fig. 1a-c). The patches gradually merge and then develop laterally while beginning to migrate upslope over progressive generations. Finally a series of migratory bands have formed and are oriented perpendicular to the direction of the slope (Fig. 1d). At this point we commence simulation of the erosion process to assess its impact on the banded pattern. In the context of natural systems, this can occur when sudden soil disturbance occurs as a result of intensified grazing, for 


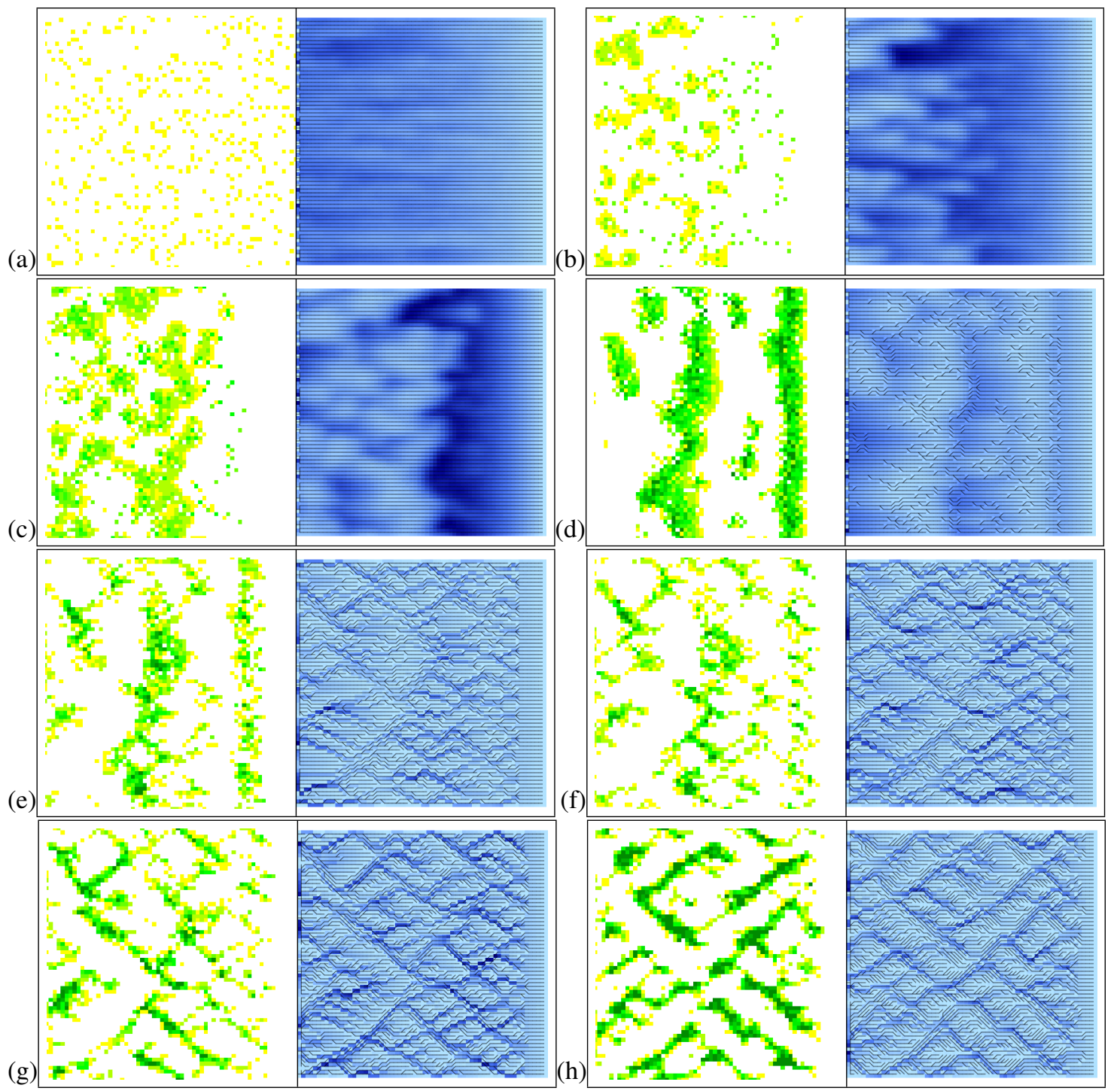

Figure 1: Sequential plan views of vegetation (left) and surface water discharge (right), including flow paths (black lines) showing band formation prior to erosion (a)-(c) and from the imposition of erosion processes (d)-(h). The general elevation decreases from right to left. The spatial scale is $64 \mathrm{~m} \times 64$ $\mathrm{m}$. The color scale for vegetation denotes young (yellow) and fully mature plants (dark green) while for discharge, light blue is low discharge and dark blue high surface water flow. Parameters are summarized in Table 1.

Table 1: Table of parameters used in simulations

\begin{tabular}{lclclc}
\hline Parameter & Value & Parameter & Value & Parameter & Value \\
\hline$k_{f}\left[\mathrm{~m}^{-1}\right]$ Case 1 & 0.6 & $b_{\max }\left[\mathrm{kg} \mathrm{m}^{-2}\right]$ & 4.5 & $E_{s}\left[\mathrm{~m} \mathrm{yr}^{-1}\right]$ & 0.05 \\
$k_{f}\left[\mathrm{~m}^{-1}\right]$ Case 2 & 2.6 & $\Delta b\left[\mathrm{~kg} \mathrm{~m}^{-2}\right]$ & 0.5 & $P\left[\mathrm{~m} \mathrm{yr}^{-1}\right]$ & 0.4 \\
$K_{0}\left[\mathrm{~m} \mathrm{yr}^{-1}\right]$ & 0.11 & $T_{\max }\left[\mathrm{m} \mathrm{yr}^{-1}\right]$ & 0.876 & $D\left[\mathrm{~kg} \mathrm{~m}^{2} \mathrm{yr}^{-1}\right]$ & 2.2 \\
$K_{\max }\left[\mathrm{m} \mathrm{yr}^{-1}\right]$ & 3.52 & $T_{c}\left[\mathrm{~m} \mathrm{yr}^{-1}\right]$ & 0.2 & $\rho_{b}\left[\mathrm{~kg} \mathrm{~m}^{-3}\right]$ & 2650 \\
$k_{c}\left[\mathrm{~m}^{-1}\right]$ & 1.0 & $w_{c}[\mathrm{~m}]$ & 0.12 & $n\left[\mathrm{~m}^{3} \mathrm{~m}^{-3}\right]$ & 0.3 \\
\hline
\end{tabular}




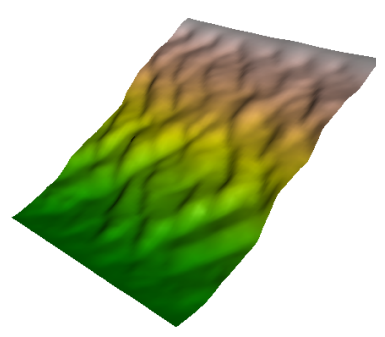

(a) Case 1: topography

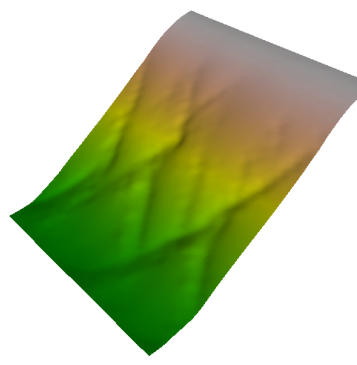

(b) Case 2: topography

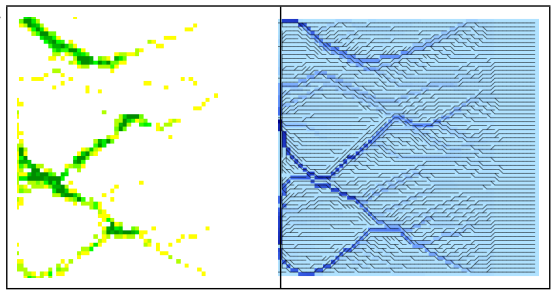

(c) Case 2: Vegetation and drainage

Figure 2: Final topography as in Case 1 (a) and Case 2 (b) with its associated vegetation and drainage pattern (c).

example. Early in the onset of erosion the bands maintain their structure as there has been only minor and small scale modification of surface water flow directions (Fig 1d). Progressively however, these minor deviations are reinforced by continued flow accumulation leading to the development of a fluvial network. As a result, the bands begin to deteriorate (Fig. 1e). Places with sufficient flow accumulation are areas where plants find favorable locations to establish and conversely where the cumulative discharge to a point is insufficient plants loose biomass and die or fail to establish. Over time these ecohydrological feedbacks lead to the development of an irregular and discontinuous network of plants aligned along the major drainage lines in the landscape (Fig. 1f-h).

The final pattern, a slowly migrating sequence of meandering channels, occupied by plants, contains a regular spatial scale separating vegetated sites. This is the first time that a model coupling self-organised vegetation on arid hills with geomorphological processes has suggested the formation of patterns other than those known to occur on smooth landscapes, namely spots, holes, labyrinths, or bands. A complete classification of patterns of landform and vegetation, associated with the parameter space, is required but is beyond the scope of this paper.

Between, the drainage/vegetation lines the topography is composed of small mounds, part of which are convex shaped, a sign that diffusive transport may be dominating sediment movement there. In addition, within the channels, surface water discharge remains at a similar level from near the top of the hill, through to the outlet, and is everywhere less than the maximum discharge at earlier times. While a definitive assessment of this requires a more comprehensive analysis than possible here, it is suggestive that the self-organising process of plant and landscape feedbacks is tending, over time, towards a flow regime with a low energy configuration [Paik and Kumar, 2008].

When instead plants have a more localised impact on hydraulic conductivity $\left(k_{f}=2.6 \mathrm{~m}^{-1}\right.$ as opposed to $k_{f}=0.6 \mathrm{~m}^{-1}$ in the previous example) the pattern and topography look very different at the same period (Fig. 2). Instead of the mounded topography of Case 1, the landscape is much smoother, and weakly etched by just a few drainage lines.

\section{Conclusions}

Ecohydrological feedbacks between plants and soil in water limited systems lead not only to selforganised vegetation patterns but they can also interact with the landform leading to complex spatiotemporal dynamics. This may have profound implications for understanding the resilience of such systems to disturbance and climate change. Incorporating diversity in species and their water use strategies is also under-research in the area of self-organised patterns and may add to the complexity of such systems. The development and testing of models like this with field observations will improve our ability to manage sensitive semi-arid ecosystems. 


\section{ACKNOWLEDGMENTS}

This research was supported under the Australian Research Council Linkage Projects (project no. LP0774881) in conjunction with Newcrest Mining Ltd. and Minerals and Energy Research Institute of Western Australia (Project M381) funding schemes.

\section{REFERENCES}

Bedford, D. R., E. E. Small, (2008). Spatial patterns of ecohydrologic properties on a hillslope-alluvial fan transect, central New Mexico. Catena 73, 34-48.

Boer, M. and J. Puigdefabregas, (2005). Effects of spatially structured vegetation patterns on hillslope erosion in a semiarid Mediterranean environment: a simulation study. Earth Surface Process. Landforms 30, 149-167.

Borgogno, F., P. D’Odorico, F. Laio, and L. Ridolfi (2009). Mathematical models of vegetation pattern formation in ecohydrology. Rev. Geophys. 47, RG1005.

Cammeraat, L.H. and A.C. Imeson, (1999). The evolution and significance of soil-vegetation patterns following land abandonment and fire in Spain. Catena 37, 107-127.

Dunne, T., W. Zhang, and B. F. Aubry, (1991). Effects of rainfall, vegetation, and microtopography on infiltration and runoff. Water Resour. Res. 9, 2271-2285.

Gallart, F., J. Puigdefabregas, and G. del Barrio, (1993). Computer simulation of high mountain terracettes as interaction between vegetation growth and sediment movement. Catena 20, 529-542.

Gwenzi, W. (2011). Ecohydrological controls on the water balance of a mine soil cover system. PhD Thesis, The University of Western Australia .

Klausmeier, C. A., (1999). Regular and irregular patterns in semiarid vegetation. Science 284, 1826-1828.

Lavee, H., and A. Yair (1990). Spatial variability of overland flow in a small arid basin. in Erosion, Transport and Deposition Processes, IAHS Publ. no. 189, 105-120.

Lefever, R., and O. Lejeune (1997). On the origin of tiger bush. Bull. Math. Biol. 59(2), 263-294.

Ludwig, J. A., R. Bartley, A. A. Hawdon, B. N. Abbott and D. McJannet, (2007). Patch configuration nonlinearly affects sediment loss across scales in a grazed catchment in north-east Australia. Ecosyst. 10, 839-845.

Ludwig, J. A., B. P. Wilcox, D. D. Breshears, D. J. Tongway, and A. C. Imeson, (2005). Vegetation patches and runoff-erosion as interacting ecohydrological processes in semiarid landscapes. Ecol. 86(2), 288-297

Marston, M. A.,(2010). Geomorphology and vegetation on hillslopes: Interactions, dependencies, and feedback loops. Geomorph. 116, 206-217.

Paik, K. P. Kumar, (2008). Emergence of self-similar tree network organization. Complexity 13(4), 30-37.

Paik, K., (2008). Global search algorithm for nondispersive flow path extraction. J. Geophys. Res. 113 F04001.

Puigdefabregas, J., (2005). The role of vegetation patterns in structuring runoff and sediment fluxes in drylands. Earth Surf. Process. Landforms 30, 133-147.

Puigdefabregas, J., A. Sole, L. Gutierrez, G. del Barrio and M. Boer, (1999). Scales and processes of water and sediment redistribution in drylands: results from the Rambla Honda field site in Southeast Spain. Earth-Science Rev. 48, 39-70.

Sanchez, G. and J. Puigdefabregas, (1994). Interactions of plant growth and sediment on slopes in a semi-arid environment. Geomorph. 9, 243-260.

Saco, P., G. R. Hancock and G. R. Wilgoose, (2007). Eco-geomorphology of banded vegetation patterns in arid and semi-arid regions. Hydrol. Earth Sys. Sci. 11(6), 1717-1730.

Stomph, T. J., N. de Ridder, T. S. Steenhuis, and N. C. van de Giesen (2002). Scale effects of Hortonian overland flow and rainfall-runoff dynamics: Laboratory validation of a process-based model. Earth Surf. Process. Landforms 27, 847-855. 